\title{
Which patient-specific and surgical characteristics influence postoperative pain after THA in a fast-track setting?
}

Yvon M. den Hartog ${ }^{1 *}$, Gerjon Hannink ${ }^{2} \mathbb{D}$, Nick T. van Dasselaar ${ }^{3}$, Nina M. Mathijssen ${ }^{1}$ and Stephan B. Vehmeijer ${ }^{1}$

\begin{abstract}
Background: In our hospital a fast-track setting including a multimodal pain protocol is used for total hip arthroplasty (THA). Despite this multimodal pain protocol there is still a large range in reported postoperative pain between patients, which hinders mobilization and rehabilitation postoperatively. The goal of this study was to identify which patient-specific and surgical characteristics influence postoperative pain after THA in a fast-track setting.

Methods: All 74 patients with osteoarthritis of the hip who underwent primary THA procedure by anterior supine intermuscular approach between November 2012 and January 2014 were included in this prospective cohort study. The protocol for pain medication was standardized.

Postoperative pain determined with the Numeric Rating Score was collected at 17 standardized moments. Linear mixed models were used to examine potential patient-specific and surgical factors associated with increased postoperative pain.
\end{abstract}

Results: Pain patterns differed substantially across individuals. Adjusted for other variables in the model, preoperative use of pain medication (regression coefficient $0.78(95 \% \mathrm{Cl} 0.28-1.26) ; p=0.005)$ and preoperative neuropathic pain scored by DN4 (regression coefficient $0.68(95 \% \mathrm{Cl} 0.15-1.20) ; p=0.02)$ were the only factors significantly associated with higher postoperative pain scores.

Conclusions: The knowledge of which factors are associated with higher postoperative pain scores after THA in a fast-track setting may help optimizing perioperative postoperative pain management and preoperative education of these patients.

Trial registration: The study was retrospectively registered in the ISRCTN registry under identifier ISRCTN15422220 (date of registration: July 25, 2017).

Keywords: Total hip arthroplasty, Fast-track, Multimodal pain protocol, Pain management, Postoperative pain

\section{Background}

Total hip arthroplasty (THA) is associated with considerable postoperative pain [1]. Almost all pain after surgery arises as a result of tissue damage at the surgical site [2]. This postoperative pain hinders early mobilization and rehabilitation with subsequent consequences on mobility and overall recovery [3]. In the last few years fast-track protocols have been introduced worldwide for elective primary THA. These are partly based on pain management protocols and include a rigorous perioperative pain management

\footnotetext{
* Correspondence: yvondenhartog@hotmail.com

${ }^{1}$ Department of Orthopaedic Surgery, Reinier de Graaf Hospital, Delft, the Netherlands

Full list of author information is available at the end of the article
}

program, which allow for an optimized perioperative period $[4,5]$. In 2009, a fast-track protocol including a multimodal pain protocol was successfully introduced in our teaching hospital [6]. The multimodal pain protocol, developed to reduce acute postoperative pain to enable quick mobilization and rehabilitation included paracetamol, celecoxib, gabapentine, dexamethasone and esketamine [7-12]. Furthermore, we use the anterior supine intermuscular (ASI) approach for THA procedures in our hospital. Since this approach uses both an intermuscular and internervous plane and causes less surgical trauma, lower postoperative pain scores and less pain medication consumption have been described for this approach [13-18]. Despite the introduction of a multimodal pain protocol and use of the 
ASI approach, there is still a large range in reported postoperative pain between patients.

Previous studies have shown that specific patient- and provider characteristics could influence postoperative pain [19-27]. Only one of these studies reported solely on postoperative pain after primary THA [21]. None of these studies were performed in a fast-track setting and no multimodal pain protocols developed to reduce acute postoperative pain were included in these studies.

The proper identification of patients who are at risk to experience more postoperative pain directly after primary THA might provide details for further optimization of postoperative pain management and preoperative education of these patients. Therefore, the goal of this study was to identify which patient-specific and surgical characteristics influence postoperative pain after primary THA by ASI approach in a fast-track setting including a multimodal pain protocol.

\section{Methods}

All 74 patients with osteoarthritis (72 patients with primary osteoarthritis, 2 patients with secondary osteoarthritis) of the hip who underwent primary THA procedure by ASI approach between November 2012 and January 2014 were included in this prospective cohort study. All procedures were performed in a fast-track setting, by one experienced orthopedic hip surgeon (SBV). Patients with neurological conditions which potentially influence pain perception; American Society of Anaesthesiologists (ASA) classification III/IV; medical contra-indication for spinal anesthesia; cardiovascular impairment in the present or past; known allergy against any element of the medication that is given for the multimodal pain protocol; abuse of alcohol or drugs; rheumatoid arthritis; BMI $>40 \mathrm{~kg} / \mathrm{m}^{2}$; and patients with cognitive impairment were excluded.

As part of the fast-track setting, all patients joined a patient education program prior to surgery. All patients received spinal anesthesia with a low dose of bupivacaine (6-8 mg intrathecally). Propofol was administered for sedation and to allow a single shot of esketamine. The multimodal protocol for perioperative pain medication was standardized (Table 1). Before discharge, adequate pain relief had to be achieved by oral pain medication: the Numeric Rating Scale (NRS) for pain had to be below 3 in rest and below 5 during mobilization (NRS; 0 to 10 , best to worst).

Postoperative pain determined with the NRS was collected at 17 standardized moments, from $1 \mathrm{~h}$ after surgery until the afternoon of the second day after surgery (Fig. 1). The study protocol was approved by our local Ethics Committee (2012-000989-37/NL39970.098.12). The study was retrospectively registered in the ISRCTN
Table 1 The standardized multimodal protocol for perioperative pain medication

\begin{tabular}{|c|c|}
\hline Timing & Medication \\
\hline \multirow[t]{3}{*}{$2 \mathrm{~h}$ before surgery } & $\begin{array}{l}\text { Paracetamol (acetaminophen) } \\
1000 \text { mg per os. }\end{array}$ \\
\hline & $\begin{array}{l}\text { Celecoxib (Celebrex }{ }^{\oplus}{ }^{\text {a }} 400 \mathrm{mg} \\
\text { per os. }\end{array}$ \\
\hline & Gabapentin 600 mg per os. \\
\hline \multirow[t]{2}{*}{ Just before surgery } & Dexamethasone $0.15 \mathrm{mg} / \mathrm{kg}$ iv. ${ }^{\mathrm{b}}$ \\
\hline & Esketamine $15 \mathrm{mg}$ iv. \\
\hline $4 \mathrm{~h}$ after surgery & $\begin{array}{l}\text { Paracetamol (acetaminophen) } \\
1000 \text { mg per os. }\end{array}$ \\
\hline \multirow[t]{2}{*}{$8 \mathrm{~h}$ after surgery } & $\begin{array}{l}\text { Paracetamol (acetaminophen) } \\
1000 \text { mg per os. }\end{array}$ \\
\hline & Gabapentin 300 mg per os. \\
\hline Before the night & Tramadol 100 mg supp. \\
\hline \multirow[t]{3}{*}{ Day 1} & $\begin{array}{l}\text { Paracetamol (acetaminophen) } \\
1000 \text { mg per os } 4 \text { times a day. }\end{array}$ \\
\hline & $\begin{array}{l}\text { Celecoxib (Celebrex }{ }^{\oplus)} \text { a } 200 \mathrm{mg} \\
\text { per os in the morning. }\end{array}$ \\
\hline & $\begin{array}{l}\text { Gabapentin } 300 \mathrm{mg} \text { per os in the } \\
\text { morning. }\end{array}$ \\
\hline \multirow[t]{2}{*}{ After day 1} & $\begin{array}{l}\text { Paracetamol (acetaminophen) } \\
1000 \text { mg per os } 4 \text { times a day } \\
\text { (with a maximum of } 2 \text { weeks). }\end{array}$ \\
\hline & $\begin{array}{l}\left.\text { Celecoxib (Celebrex }{ }^{\circledast}\right)^{\text {a }} 200 \mathrm{mg} \\
\text { per os in the morning (until } 2 \text { weeks } \\
\text { after surgery). }\end{array}$ \\
\hline Rescue medication & $\begin{array}{l}\text { Celecoxib }\left(\text { Celebrex }^{\oplus}\right)^{\mathrm{a}} 200 \mathrm{mg} \text { per } \\
\text { os extra after the first night } \\
\left.\text { Piritramid (Dipidolor }{ }^{\oplus}\right) 10 \mathrm{mg} \text { im, which } \\
\text { could be repeated every } 4 \mathrm{~h} \text {. }\end{array}$ \\
\hline
\end{tabular}

The standardized multimodal protocol for perioperative pain medication was determined based on literature [7-12]

${ }^{a}$ In combination with celecoxib (Celebrex ${ }^{\circ}$ ) all patients will receive omeprazol $20 \mathrm{mg}$ per os once a day as prophylaxis. When the patient was already using a proton pomp inhibitor before admittance no omeprazol was administered ${ }^{b}$ Dexamethasone solution in $50 \mathrm{~cm}^{3}$ saline is administered slowly to avoid adverse side effects like severe perianal pain

registry under identifier ISRCTN15422220 (date of registration: July 25, 2017).

Potential factors associated with increased postoperative pain (gender; ASA classification; age; BMI; diabetes mellitus (DM); surgery time; incision length; living situation; preoperative pain determined with the NRS, preoperative use of pain medication; use of antidepressants; as well as preoperative scores of the neuropathic pain diagnostic questionnaire (DN4), and Amsterdam Preoperative Anxiety and Information Scale (APAIS) for anxiety and information requirements) were examined with univariable linear mixed models for repeated measures. Decision to include these variables was based on guidance from directed acyclic graphs [28]. Based on the criteria in the original article about the APAIS by Moerman and others [29], the APAIS anxiety scale was dichotomized (4-10: no, 11-20: yes), and the APAIS 


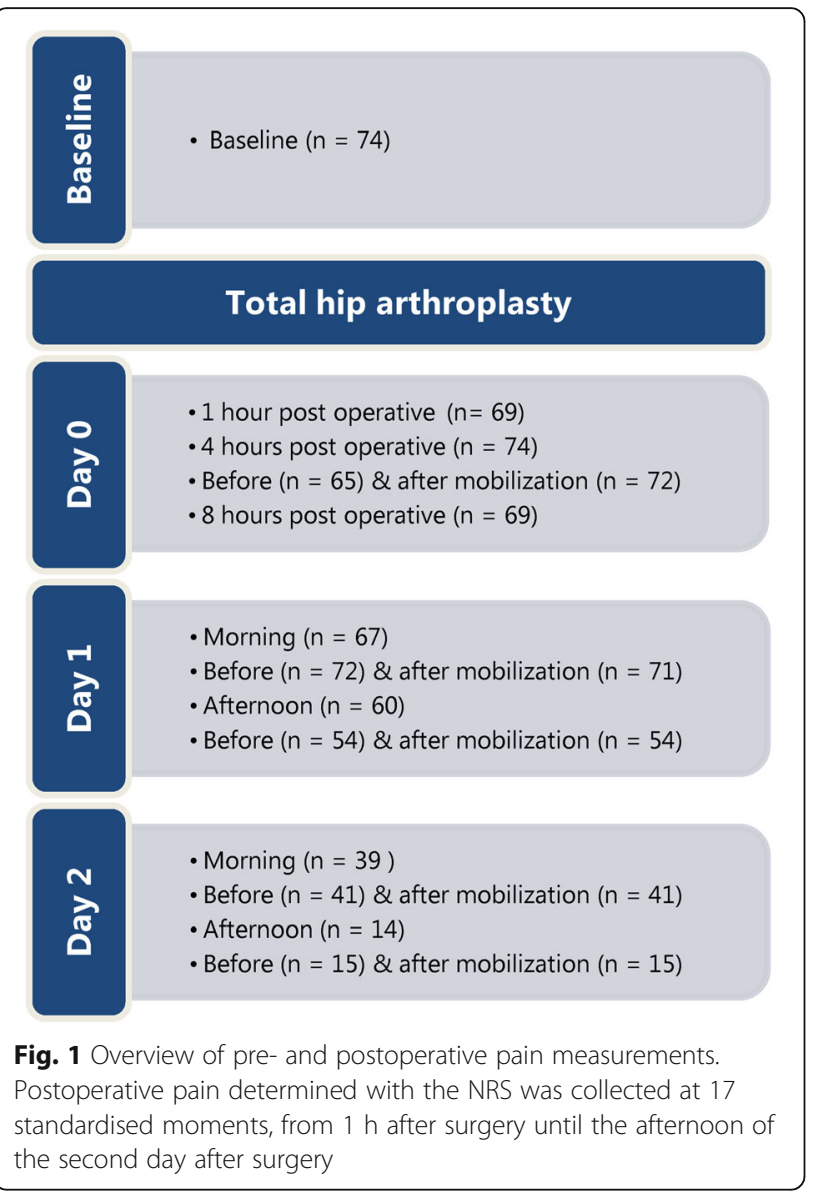

need-for-information scale was divided into three categories (2-4: no or little, 5-7: average, and 8-10: high). The DN4 questionnaire score was dichotomized (1-3 unlikely; 4-7 likely) [30, 31].

Factors that were associated with the outcome in univariable analyses ( $p$-values $<0.20)$ were included in multivariable analyses. In the multivariable analyses $p$-values less than 0.05 were considered significant. Missing data were assumed to be missing at random. Regression coefficients are presented with their 95\% confidence intervals. The statistical analyses were performed using $R$ version 3.1.2 with package 'nlme' [32, 33].

\section{Results}

Mean age of all patients was 67.1 year (range 42.7-84.6) and mean BMI was $27.1 \mathrm{~kg} / \mathrm{m}^{2}$ (range 20.1-38.9). Mean LOS was 1.8 nights (range $1-7$ ). Most patients lived together with cohabitants $(n=58 ; 78.4 \%)$ and were discharged to their own home $(n=72 ; 97.3 \%)$. Patient characteristics are listed in Table 2.

Seventy-three patients received an uncemented prostheses (Taperloc ${ }^{\circ}$ femoral prosthesis and an Universal ${ }^{\circ}$ cup, both Biomet, Warsaw, In, USA), one patient received a cemented prosthesis because of inferior bone
Table 2 Patient characteristics for the total group of 74 patients undergoing primary total hip arthroplasty

\begin{tabular}{|c|c|c|}
\hline & & $\begin{array}{l}\text { Total n (\%) } \\
n=74\end{array}$ \\
\hline Age (year) & & $67.1(42.7-84.6)^{a}$ \\
\hline BMI $\left(\mathrm{kg} / \mathrm{m}^{2}\right)$ & & $27.1(20.1-38.9)^{a}$ \\
\hline Gender & male & $36(48.6 \%)$ \\
\hline ASA classification & ASA2 & $47(63.5 \%)$ \\
\hline Surgery time (minutes) & & $79.2(49-116)^{a}$ \\
\hline Diabetes Mellitus & & $7(9.5 \%)$ \\
\hline Incision length (cm) & & $9.97(7.5-12.0)^{a}$ \\
\hline Living situation & with cohabitants & $58(78.4 \%)$ \\
\hline Preoperative antidepressants use & & $4(5.4 \%)$ \\
\hline Preoperative pain medication use & & $50(67.6 \%)$ \\
\hline Preoperative pain (NRS) ${ }^{b}$ & & $5.26(0-9)^{a}$ \\
\hline DN4 & likely & $16(21.6 \%)$ \\
\hline APAIS anxiety & yes & $15(23.1 \%)$ \\
\hline \multirow[t]{3}{*}{ APAIS information } & no/little & $24(37.5 \%)$ \\
\hline & average & $24(37.5 \%)$ \\
\hline & high & $16(25.0 \%)$ \\
\hline
\end{tabular}

${ }^{a}$ mean (range)

${ }^{\mathrm{b}} n=72$ patients

quality due to severe osteoporosis. (Exceed Muller cup and a Taperloc ${ }^{\circ}$ femoral prosthesis, both Biomet, Warsaw, In, USA).

Pain patterns differed substantially across individuals. Moreover, pain varied across the standardized moments (Table 3). Adjusted for the other factors in the model, preoperative use of pain medication (regression coefficient 0.78 (95\% CI $0.28-1.26$ ); $p=0.005$ ) and preoperative neuropathic pain scored by DN4 (regression coefficient 0.68 (95\% CI $0.15-1.20) ; p=0.02$ ) were the only factors that were significantly associated with higher postoperative pain scores (Table 4).

\section{Discussion}

The aim of this study was to identify which patientspecific and surgical characteristics influence postoperative pain after primary THA by ASI approach in a fasttrack setting, using a multimodal pain protocol which was developed to reduce acute postoperative pain to enable quick mobilization and rehabilitation. The only two factors associated with increased postoperative pain adjusted for the other factors in the model, were preoperative use of pain medication (regression coefficient 0.78 (95\% CI 0.28-1.26); $p=0.005$ ) and preoperative neuropathic pain scored by DN4 (regression coefficient 0.68 (95\% CI 0.15-1.20); $p=0.02$ ).

In our study, we used a multimodal pain protocol, including paracetamol, celecoxib, gabapentin, dexamethasone and esketamine [7-12]. This pain protocol is part 
Table 3 Pain scores determined with the NRS at the standardized moments

\begin{tabular}{llll}
\hline NRS & & $\mathrm{N}$ & mean (range) \\
\hline Preoperative & & 72 & $5.26(0.0-9.0)$ \\
Day of surgery & $1 \mathrm{~h}$ & 69 & $1.51(0.0-8.0)$ \\
& $4 \mathrm{~h}$ & 74 & $2.97(0.0-9.0)$ \\
& Before mobilization & 69 & $2.62(0.0-6.0)$ \\
& After mobilization & 65 & $2.93(0.0-10.0)$ \\
& $8 \mathrm{~h}$ & 72 & $2.40(0.0-8.0)$ \\
Day 1 & Morning & 67 & $1.63(0.0-5.0)$ \\
& Before mobilization & 72 & $1.71(0.0-7.0)$ \\
& After mobilization & 71 & $2.25(0.0-9.0)$ \\
& Afternoon & 60 & $1.57(0.0-6.0)$ \\
& Before mobilization & 54 & $1.26(0.0-4.0)$ \\
& After mobilization & 54 & $1.73(0.0-6.0)$ \\
Day 2 & Morning & 39 & $2.00(0.0-7.0)$ \\
& Before mobilization & 41 & $1.54(0.0-6.0)$ \\
& After mobilization & 41 & $1.84(0.0-4.5)$ \\
& Afternoon & 14 & $1.82(0.0-3.0)$ \\
& Before mobilization & 15 & $1.27(0.0-3.0)$ \\
& After mobilization & 15 & $1.93(0.0-4.0)$ \\
\hline
\end{tabular}

of a fast-track setting and is developed to reduce acute postoperative pain to enable patients to quickly mobilize and rehabilitate in an optimized and safe perioperative period $[4,5]$. Mean postoperative pain score determined with the NRS collected at 17 standardized moments, varied from 1.51 (range 0.0-8.0) to 2.97 (range 0.0-9.0). These results demonstrate that the use of our multimodal pain protocol enables adequate postoperative pain relief in which patients are able to mobilize and rehabilitate quickly. However, despite this pain protocol, a large range in reported postoperative pain between patients still exists, including some outliers with high postoperative pain scores.

Pain has been described to be a sensory and emotional experience that is influenced by multiple factors [34, 35]. Although several other studies reported on effects of specific patient- and provider characteristics on postoperative pain [19-27], none of these studies were performed in a fast-track setting with a multimodal pain protocols developed to reduce acute postoperative pain (and hence enable early mobilization), were included in these studies. Since no literature reports on the effect of potential factors associated with increased postoperative pain in a fast-track setting, our model included various potential factors that have been described to be associated with postoperative pain based on a non-fast-track setting [19-27, 36]. The use of a multimodal pain protocol in our study might have influenced the effects of these characteristics on postoperative pain and could be a reason for discrepancy between our results and results of these other studies.

Preoperative use of pain medication provides information on the preoperative pain levels of patients and has been shown to be associated with more severe postoperative pain [26, 27]. Our study supports these findings. In contrast,

Table 4 Regression coefficients with 95\% Cls for potential factors associated with increased postoperative pain after THA in a fast-track setting

\begin{tabular}{|c|c|c|c|c|c|}
\hline & & \multicolumn{2}{|l|}{ Univariable analyses } & \multicolumn{2}{|l|}{ Multivariable analysis } \\
\hline & & coefficient (95\% Cl) & $p$-value & coefficient (95\% Cl) & $p$-value \\
\hline \multicolumn{2}{|l|}{ Age } & $0.006(-0.02-0.03)$ & 0.66 & - & - \\
\hline \multicolumn{2}{|l|}{$\mathrm{BMI}$} & $0.03(-0.03-0.09)$ & 0.28 & - & - \\
\hline Gender & male vs. female & $-0.31(-0.79-0.18)$ & 0.22 & - & - \\
\hline ASA classification & ASA2 vs. ASA1 & $0.30(-0.21-0.80)$ & 0.25 & - & - \\
\hline \multicolumn{2}{|l|}{ Surgery time } & $-0.01(-0.03-0.0005)$ & 0.06 & $0.0004(-0.01-0.01)$ & 0.96 \\
\hline \multicolumn{2}{|l|}{ Diabetes Mellitus } & $-0.05(-0.88-0.78)$ & 0.92 & - & - \\
\hline \multicolumn{2}{|l|}{ Incision length } & $0.02(-0.26-0.31)$ & 0.89 & - & - \\
\hline Living situation & with cohabitants vs. alone & $0.53(-0.05-1.10)$ & 0.08 & $0.50(-0.08-1.07)$ & 0.11 \\
\hline Preoperative antidepressants use & yes vs. no & $0.66(-0.39-1.71)$ & 0.22 & - & - \\
\hline Preoperative pain medication use & yes vs. no & $0.68(0.18-1.18)$ & 0.009 & $0.78(0.28-1.26)$ & 0.005 \\
\hline \multicolumn{2}{|l|}{ Preoperative pain } & $0.10(-0.01-0.21)$ & 0.08 & $-0.02(-0.13-0.09)$ & 0.73 \\
\hline DN4 & likely vs. unlikely & $0.70(0.13-1.28)$ & 0.02 & $0.68(0.15-1.20)$ & 0.02 \\
\hline APAIS anxiety & yes vs. no & $-0.06(-0.67-0.54)$ & 0.84 & - & - \\
\hline \multirow[t]{2}{*}{ APAIS information } & average vs. no/little & $-0.02(-0.61-0.56)$ & 0.93 & $-0.21(-0.74-0.31)$ & 0.45 \\
\hline & high vs. no/little & $0.50(-0.16-1.15)$ & 0.15 & $0.45(-0.12-1.02)$ & 0.15 \\
\hline
\end{tabular}

Factors that were associated with the outcome in univariable analyses ( $p$-values $<0.20$ ) were included in a multivariable linear mixed model for repeated measures. In the multivariable analyses $p$-values $<0.05$ were considered significant 
another study on postoperative pain 12 to $24 \mathrm{~h}$ after elective abdominal surgery, demonstrated no effect of preoperative use of pain medication on postoperative pain [23].

Our multimodal protocol for postoperative pain medication was standardized for all patients. The effect of this pain protocol might therefore not be sufficient for single patients who are used to pain medication. On the other hand, in a study on postoperative pain after thoracic surgery a decrease in postoperative pain medication use for patients who used pain medication preoperatively was found [37].

DN4 [30, 31] is a validated questionnaire for neuropathic pain, which was preoperatively scored for all patients in our study. The differences between neuropathic pain and non-neuropathic (nociceptive) pain have been described in literature [30]. Osteoarthritis, the main indication for THA in our study, causes non-neuropathic pain [30]. Patients who experience non-neuropathic pain from osteoarthritis preoperatively, are more likely to benefit from THA and will experience less pain postoperatively. Since preoperative neuropathic pain is not caused by osteoarthritis of the hip [30], THA will probably not resolve this neuropathic pain. As a consequence, these patients will be more likely to experience more postoperative pain after primary THA.

In the present study, none of the other factors were significantly associated with postoperative pain. All of these potential factors have been described to be associated with postoperative pain in non-fast-track setting studies [19-27, 36]. Contrasting results on the effect of age on postoperative pain have been reported in literature, including an association between younger age and a higher level of postoperative pain [20, 23, 24, 27] as well as a lack of effect of age on the level of postoperative pain $[26,38]$.

BMI has been shown to be associated with an increased inflammatory response [38], which is related to higher levels of postoperative pain [39], whereas others demonstrated no effect of BMI on postoperative pain scores $[24,39,40]$. In our study we excluded patients with $\mathrm{BMI}>40 \mathrm{~kg} / \mathrm{m}^{2}$, which might be a reason for lack of effect of BMI on postoperative pain.

Regarding gender, contrasting results on the effect on postoperative pain have been reported in literature as well. These results include both higher postoperative pain for female patients $[24,27,38]$ and no effect of gender on postoperative pain [22, 23, 25, 26].

Higher ASA classification has also been shown to be associated with increased postoperative pain [23]. However, in our study we only included patients with ASA classification I or II, which might be a reason for lack of effect of ASA classification on postoperative pain.

An increased incision length results in increased tissue damage, and might subsequently result in increased postoperative pain. This relation has been described in literature [24]. In our study the ASI approach was used. Since this approach uses both an intermuscular and internervous plane, less surgical trauma and hence lower postoperative pain scores and less pain medication consumption have been described [13-18].

Use of antidepressants provides information on patients' mental state, which could be predictive for the patients' response on pain medication and pain experience [25]. Moreover, in literature depression symptoms have been mentioned to be related to higher level of postoperative pain $[23,38,41]$.

Furthermore, we used different validated questionnaires preoperatively for all patients to define preoperative pain and pain characteristics, including the APAIS [29]. Anxious patients respond differently to anesthesia and pain than non-anxious patients and therefore require larger doses of anaesthetics [19, 20, 25, 42, 43]. It has been reported that the anxiety/'worry' component of the APAIS is positively associated with the occurrence of early postoperative pain, whereas a strong information seeking behavior reduces the incidence of severe postoperative pain [24]. This is in contrast to others who report that patients who require more information about impending discomforts preoperatively may sensitize the individual to the experience [19].

Some potential limitations of our study should be discussed. First, although only 74 patients were included in the present study, a strength of the study is that we used linear mixed models. These do not only model the correlation between repeated measures of the same patient, they also assess fluctuations in postoperative pain over time. Second, although others investigated effects of occupation and/or level of education [19, 23, 40, 41], SF-36 [24], and heart rate and blood pressure [36] on postoperative pain, we were not able to include these variables in our model, because these variables were not reported in a consistent way in the patient files. Third, one single orthopaedic surgeon performed all surgical procedures which reduces variation in operative technique, however, could potentially mask systematic faults in surgical technique or surgical approach. Fourth, the indication of THA could be questioned in patients who do not need any preoperative pain medication. In our study, 50 out of 76 reported to use preoperative pain medication. National and international evidence-based guidelines for hip and knee OA recommend to start with (a combination of) conservative treatments. Despite the recommendation in guidelines to start with conservative treatments and only use surgical intervention if a patient does not respond sufficiently to conservative treatment options, the use of conservative treatments in daily practice is suboptimal [44-47]. It has been shown that conservative treatments were not fully exploited in $81 \%$ 
of the patients who were referred to specialized knee/hip OA outpatient clinics [44]. Even worse, a recent study showed that only $10 \%$ of the patients in orthopaedic practice received all recommended non-surgical treatments before surgery [48].

A qualitative systematic review of Ip and others [36] identified factors associated with postoperative pain and analgesic consumption. Type of surgery was an important predictive factor for postoperative pain. This suggests that results of our study are applicable for primary THA. Furthermore, this could be another reason for the discrepancy between different studies describing postoperative pain after different types of surgery, besides differences in the pain protocol used.

\section{Conclusion}

Only preoperative use of pain medication and preoperative neuropathic pain were associated with increased postoperative pain after primary THA in a fast-track setting, including a multimodal pain protocol which was developed to reduce acute postoperative pain to enable quick mobilization and rehabilitation. This knowledge provides further details for optimization of postoperative pain management and preoperative patient education.

\section{Abbreviations}

APAIS: Amsterdam preoperative anxiety and information scale;

ASA: American Society of Anaesthesiologists; ASI: Anterior supine intermuscular; BMI: Body mass index; DM: Diabetes mellitus; DN4: Douleur neuropathique en 4 questions; LOS: Length of hospital stay; NRS: Numeric rating scale; THA: Total hip arthroplasty

\section{Acknowledgements}

We would like to show our gratitude to the patients who made this study possible.

\section{Funding}

No funding was received.

\section{Availability of data and materials}

The datasets generated and/or analysed during the current study are not publicly available but are available from the corresponding author $(\mathrm{YMdH})$ on reasonable request.

\section{Authors' contributions}

All authors (YMdH, GH, NTVD, NMM, SBV) designed the study and interpreted data. YMdH and $\mathrm{GH}$ made the statistical analyses. YMdH, GH and NMM wrote the first version of the manuscript. All authors critically revised different versions of the manuscript. YMdH is the corresponding author. All authors read and approved the final manuscript.

\section{Ethics approval and consent to participate}

The study protocol was approved by our local Ethics Committee (METC Zuidwest Holland; 2012-000989-37/NL39970.098.12). Written informed consent was obtained from all study participants.

\section{Consent for publication}

Written consent for publication of the results was obtained from all study participants.

\section{Competing interests}

The authors declare that they have no competing of interests.

\section{Publisher's Note}

Springer Nature remains neutral with regard to jurisdictional claims in published maps and institutional affiliations.

\section{Author details}

${ }^{1}$ Department of Orthopaedic Surgery, Reinier de Graaf Hospital, Delft, the Netherlands. ${ }^{2}$ Orthopaedic Research Lab, Department of Orthopaedics, Radboud university medical center, Nijmegen, the Netherlands. ${ }^{3}$ Department of Anaesthesiology and Pain Medicine, Reinier de Graaf Hospital, Delft, the Netherlands.

Received: 28 February 2017 Accepted: 15 August 2017

Published online: 24 August 2017

\section{References}

1. Busch CA, Whitehouse MR, Shore BJ, MacDonald SJ, McCalden RW, Bourne RB. The efficacy of periarticular multimodal drug infiltration in total hip arthroplasty. Clin Orthop Relat Res. 2010:468(8):2152-9.

2. Kerr DR, Kohan L. Local infiltration analgesia: a technique for the control of acute postoperative pain following knee and hip surgery: a case study of 325 patients. Acta Orthop. 2008;79(2):174-83.

3. Kehlet $H$, Andersen $L \varnothing$. Local infiltration analgesia in joint replacement: the evidence and recommendations for clinical practice. Acta Anaesthesiol Scand. 2011:55(7):778-84.

4. Kehlet $\mathrm{H}$, Wilmore DW. Multimodal strategies to improve surgical outcome. Am J Surg. 2002;183(6):630-41.

5. Husted H, Jensen CM, Solgaard S, Kehlet H. Reduced length of stay following hip and knee arthroplasty in Denmark 2000-2009: from research to implementation. Arch Orthop Trauma Surg. 2012;132(1): 101-4.

6. den Hartog YM, Mathijssen NM, Vehmeijer SB. Reduced length of hospital stay after the introduction of a rapid recovery protocol for primary THA procedures. Acta Orthop. 2013;84(5):444-7.

7. Rasmussen ML, Mathiesen O, Dierking G, Christensen BV, Hilsted KL, Larsen TK. Multimodal analgesia with gabapentin, ketamine and dexamethasone in combination with paracetamol and ketorolac after hip arthroplasty: a preliminary study. Eur J Anaesthesiol. 2010;27(4):324-30.

8. de Oliviera GS Jr, Almeida MD, Benzon HT, RJ MC. Perioperative single dose systemic dexamethasone for postoperative pain: a meta-analysis of randomized controlled trials. Anesthesiology. 2011;115(3):575-88.

9. Lunn TH, Husted H, Solgaard S, Kristensen BB, Otte KS, Kjersgaard AG, Gaarn-Larsen L, Kehlet H. Intraoperative local infiltration analgesia for early analgesia after total hip arthroplasty: a randomized, double-blind, placebocontrolled trial. Reg Anesth Pain Med. 2011;36(5):424-9.

10. Lunn TH, Andersen L $\varnothing$, Kristensen BB, Husted H, Gaarn-Larsen L, Bandholm T, Ladelund S, Kehlet H. Effect of high-dose preoperative methylprednisolone on recovery after total hip arthroplasty: a randomized, double-blind, placebo-controlled trial. Br J Anaesth. 2013;110(1):66-73.

11. Carmichael NM, Katz J, Clarke H, Kennedy D, Kreder HJ, Gollish J, McCartney CJ. An intensive perioperative regimen of pregabalin and celecoxib reduces pain and improves physical function scores six weeks after total hip arthroplasty: a prospective randomized controlled trial. Pain Res Manag. 2013;18(3):127-32.

12. Schmidt PC, Ruchelli G, Mackey SC, Carroll IR. Perioperative gabapentinoids: choice of agent, dose, timing, and effects on chronic postsurgical pain. Anesthesiology. 2013;119(5):1215-21.

13. Alecci V, Valente M, Crucil M, Minerva M, Pellegrino CM, Sabbadini DD. Comparison of primary total hip replacements performed with a direct anterior approach versus the standard lateral approach: perioperative findings. J Orthop Traumatol. 2011;12(3):123-9.

14. Goebel S, Steinert AF, Schillinger J, Eulert J, Broscheit J, Rudert M, Nöth U. Reduced postoperative pain in total hip arthroplasty after minimal-invasive anterior approach. Int Orthop. 2012;36(3):491-8.

15. Pogliacomi F, Paraskevopoulos A, Costantino C, Marenghi P, Ceccarelli F. Influence of surgical experience in the learning curve of a new approach in hip replacement: anterior mini-invasive vs. standard lateral. Hip Ints. 2012;22(05):555-61.

16. Barrett WP, Turner SE, Leopold JP. Prospective randomized study of direct anterior vs postero-lateral approach for total hip arthroplasty. J Arthroplast. 2013;28(9):1634-8 
17. Ilchmann T, Gersbach S, Zwicky L, Clauss M. Standard transgluteal versus minimal invasive anterior approach in hip arthroplasty: a prospective, consecutive cohort study. Orthop Rev (Pavia). 2013;5(4):e31.

18. Zawadsky MW, Paulus MC, Murray PJ, Johansen MA. Early outcome comparison between the direct anterior approach and the mini-incision posterior approach for primary total hip arthroplasty: 150 consecutive cases. J Arthroplast. 2014;29(6):1256-60.

19. Scott LE, Clum GA, Peoples JB. Preoperative predictors of postoperative pain. Pain. 1983;15(3):283-93

20. Perry F, Parker RK, White PF, Clifford PA. Role of psychological factors in postoperative pain control and recovery with patient-controlled analgesia. Clin J Pain. 1994;10(1):57-63.

21. Slappendel R, Weber EW, Bugter ML, Dirksen R. The intensity of preoperative pain is directly correlated with the amount of morphine needed for postoperative analgesia. Anesth Analg. 1999;88(1):146-8.

22. Dahmani S, Dupont H, Mantz J, Desmonts JM, Keita H. Predictive factors of early morphine requirements in the post-anaesthesia care unit (PACU). Br J Anaesth. 2001;87(3):385-9.

23. Caumo W, Schmidt AP, Schneider CN, Bergmann J, Iwamoto CW, Adamatti LC, Bandeira D, Ferreira MB. Preoperative predictors of moderate to intense acute postoperative pain I patients undergoing abdominal surgery. Acta Anaesthesiol Scand. 2002;64(10):1265-71.

24. Kalkman CJ, Visser K, Moen J, Bonsel GJ, Grobbee DE, Moons KG. Preoperative prediction of severe postoperative pain. Pain. 2003;105(3):415-23.

25. Granot M, Ferber SG. The roles of pain catastrophizing and anxiety in the prediction of postoperative pain intensity: a prospective study. Clin J Pain. 2005;21(5):439-45.

26. Aubrun F, Valade N, Coriat P, Riou B. Predictive factors of severe postoperative pain in the postanesthesia care unit. Anest Analg. 2008;106(5):1535-41.

27. Liu SS, Buvanendran A, Rathmell JP, Sawhney M, Bae JJ, Moric M, Perros S, Pope AJ, Poultsides L, Della Vall CJ, Shin NS, McCartney CJ, Ma Y, Shah M, Wood MJ, Manion SC, Sculco TP. Predictors for moderate to severe acute postoperative pain after total hip and knee replacement. Int Orthop. 2012;36(11):2261-7.

28. Shrier I, Platt RW. Reducing bias through directed acyclic graphs. BMC Med Res Methodol. 2008:8:70.

29. Moerman N, van Dam FS, Muller MJ, Oosting $H$. The Amsterdam Preoperative Anxiety and Information Scale (APAIS). Anesth Analg. 1996;82(3):445-51.

30. Bouhassira D, Attal N, Alchaar H, Boureau F, Brochet B, Bruxelle J, Cunin G, Fermanian J, Ginies P, Grun-Overdyking A, Jafari SChluep H, Lantéri-Minet M, Laurent B, Mick G, Serrie A, Valade D, Vicaut E. Comparison of pain syndromes associated with nervous or somatic lesions and development of a new neuropathic pain diagnostic questionnaire (DN4). Pain. 2005;114(1-2):29-36.

31. van Seventer R, Vos C, Giezeman M, Meerding WJ, Arnould B, Regnault A, van Eerd M, Martin C, Huygen F. Validation of the Dutch version of the DN4 diagnostic questionnaire for neuropathic pain. Pain Pract. 2013;13(5):390-8.

32. R Core Team. R: a language and environment for statistical computing. Vienna: R Foundation for Statistical Computing; 2014. http://www.R-project.org/.

33. Pinheiro J, Bates D, DebRoy S, Sarkar D, R Core Team. nlme: linear and nonlinear mixed effects models. R package version. 2014;3:1-118. http://cran.r-project.org/web/packages/nlme/.

34. Melzack R, Wall P. Pain mechanisms: a new theory. Science. 1965;150(3699):971-9.

35. Loeser J, Melzack R. Pain: an overview. Lancet. 1999;353(9164):1607-9.

36. Ip HY, Abrishami A, Peng PW, Wong J, Chung F. Predictors of postoperative pain and analgesic consumption. Anesthesiology. 2009;111(3):657-77.

37. Bachiocco V, Rucci P, Carli G. Request of analgesics in post-surgical pain. Relationships to psychological factors and pain-related variables. Pain Clinic. 1996;9(2):169-79.

38. de Cosmo G, Congedo E, Lai C, Primieri P, Dottarelli A, Aceto P. Preoperative psychologic and demographic predictors of pain perception and tramadol consumption using intravenous patient-controlled analgesia. Clin J Pain. 2008;24(5):399-405.

39. Motaghedi R, Bae JJ, Memtsoudis SG, Kim DH, Beathe JC, Paroli L, YaDeau JT, Gordon MA, Maalof DB, Lin Y, Ma Y, Cunningham-Rundless S, Liu SS. Association of obesity with inflammation and pain after total hip arthroplasty. Clin Orthop Relat Res. 2014;472(5):1442-8.

40. Chia YY, Chow LH, Hung CC, Liu K, Ger LP, Wang PN. Gender and pain upon movement are associated with the requirements for postoperative patient-controlled iv analgesia: a prospective survey of 2.298 Chinese patients. Can J Anaesth. 2002;49(3):249-55.
41. Taenzer $P$, Melzack $R$, Jeans ME. Influence of psychological factors on postoperative pain, mood and analgesic requirements. Pain. 1986;24(3):331-42.

42. Williams JGL, Jones JR. Psychophysiological responses to anesthesia and operation. JAMA. 1968;203:127-9.

43. Thyer BA, Papsdorf JD, Davis R, Vallecorsa S. Autonomic correlates of the subjective anxiety scale. J Behav Ther Exp Psychiatry. 1984;15:3-7.

44. Snijders GF, den Broeder AA, van Riel PL, Straten VH, de Man FH, van den Hoogen FH. Evidence-based tailored conservative treatment of knee and hip osteoarthritis: between knowing and doing. Scand J Rheumatol. 2011:40:225-31.

45. Shrier I, Feldman DE, Gaudet MC, Rossignol M, Zukor D, Tanzer M. Conservative non-pharmacological treatment options are not frequently used in the management of hip osteoarthritis. J Sci Med Sport. 2006;9:81-6.

46. De Haan MN, Guzman J, Bayley MT, Bell MJ. Knee osteoarthritis clinical practice guidelines - how are we doing? J Rheumatol. 2007:34:2099-105.

47. Hunter DJ. Quality of osteoarthritis care for community-dwelling older adults. Clin Geriatr Med. 2010;26:401-17.

48. Hofstede SN, Vliet Vlieland TP, van den Ende CH, Nelissen RG, Marang-van de Mheen PJ, van Bodegom-Vos L. Variation in use of non-surgical treatments among osteoarthritis patients in orthopaedic practice in the Netherlands. BMJ Open. 2015;5(9):e009117.

\section{Submit your next manuscript to BioMed Central and we will help you at every step:}

- We accept pre-submission inquiries

- Our selector tool helps you to find the most relevant journal

- We provide round the clock customer support

- Convenient online submission

- Thorough peer review

- Inclusion in PubMed and all major indexing services

- Maximum visibility for your research

Submit your manuscript at www.biomedcentral.com/submit

) Biomed Central 